\title{
ESPECIFICIDADES E TRAJETÓRIAS FORMATIVAS - UMA REVISÃO DE LITERATURA
}

Isac Costa Soares

DOI: http://dx.doi.org/10.19179/2F2319-0868/2F768

SOARES, Isac Costa. Especificidades e trajetórias formativas - uma revisão de literatura. Revista da FUNDARTE. Montenegro, p.110-123, ano 20, no 40, janeiro/março de 2020.

Disponível em: http://.seer.fundarte.rs.gov.br/index.php/RevistadaFundarte/index> 31 de março de 2020. 


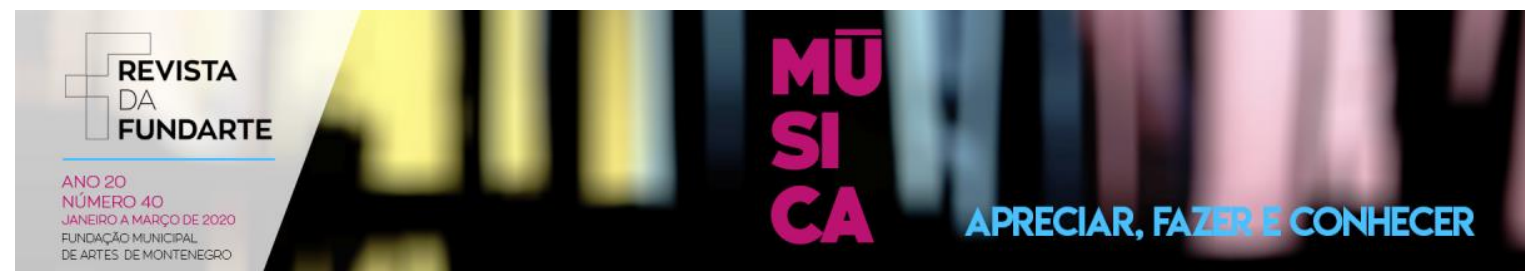

"A revisão bibliográfica é a exposição detalhada da produção cientifica já produzida sobre a temática em estudo, referida como o "estado da arte." Ela possibilita uma melhor delimitação do tema em estudo, pois, analisando-se as diversas contribuições feitas, podem se visualizar lacunas no conhecimento ou tópicos polêmicos que sugerem novas abordagens do tema. (BRUMER; et al, 2008 p. 132).

Sendo assim, trago neste artigo de revisão, trabalhos que tive identificação a partir de suas temáticas, buscando certa aproximação com o tema proposto. Além disso, procurando delimitar meu tema de pesquisa, esses trabalhos contribuíram para uma percepção mais aprofundada sobre a forma com a qual foram feitos e conduzidos.

\section{O tema da pesquisa:}

Este tema "As trajetórias formativas de trompetistas atuantes no cenário musical de Porto Alegre", está diretamente vinculado com meu percurso inicial. Comecei meus estudos musicais aos quatorze anos de idade no Projeto de educação musical popular Ouviravida ${ }^{2}$ em Alvorada-RS no bairro Umbú. Neste projeto estudei flauta doce, canto coral e percussão. Nessa época, alguns grupos de alunos da Escola de Música da OSPA (Conservatório Pablo Komlós) ${ }^{3}$ foram convidados para fazer apresentações no local onde aconteciam as aulas do projeto. Recordo-me que meu interesse pelo instrumento veio a partir desses recitais.

Certa vez, um aluno da escola de música da OSPA 4 executou o Carinhoso de Pixinguinha no trompete e ele era o único músico negro no grupo, de alguma forma

2 O Projeto Ouviravida esteve ativo entre 1999 e 2007, com o objetivo de promover o ensino gratuito de música em comunidades em situação de vulnerabilidade social e econômica. Em 2017 foi reativado e se mantém até os dias atuais 2019. Informações retiradas da página no facebook https://www.facebook.com/ouviravida/ no dia 24/06/2019.

${ }^{3}$ A escola de música da OSPA foi fundada em 1972 e teve seu fechamento em 2004. Em 2013 após nove anos de inatividade a escola retoma suas atividades. Informações retiradas do site: www.ospa.org.br no dia 29/06/2019.

${ }^{4}$ A Ospa foi fundada em 1950, tendo à sua frente o maestro Pablo Komlós, regente húngaro que a dirigiu até 1978 e foi responsável pela permanência, solidificação e prestígio adquirido pela orquestra gaúcha em todo o país. Depois do falecimento de Komlós, a Ospa teve como regentes titulares os maestros David Machado, Eleazar de Carvalho, Flávio Chamis, Cláudio Ribeiro, Íon Bressan e Isaac Karabtchevsky. Desde então mantida e administrada pelo Governo do Estado do Rio Grande do Sul, a Ospa é um órgão da Secretaria de Estado da Cultura. Possui uma extensa agenda de concertos em todo o estado, atingindo um público abrangente e diversificado. Orquestra mais antiga do país em atividades ininterruptas, sua programação é constituída pelas séries Pablo Komlós, Igrejas, Araújo Vianna, Interior, Música de Câmara, Concertos Didáticos, Ospa Jovem e concertos especiais. Informações retiradas do site: http://www.ospa.org.br/orquestra/ no dia 08/03/2020.

SOARES, Isac Costa. Especificidades e trajetórias formativas - uma revisão de literatura. Revista da FUNDARTE. Montenegro, p.110-123, ano 20, ํㅡ 40, janeiro/março de 2020.

Disponível em: http://.seer.fundarte.rs.gov.br/index.php/RevistadaFundarte/index> 31 de março de 2020. 
tive uma identificação com aquele momento, pois, aquilo me marcou de tal maneira que meu interesse pelo instrumento foi imediato. Para Castro (2004, p. 22) "Não temos negros e quase não temos pobres na música erudtia porque não há onde possam aprender instrumentos aos 7 anos de idade." Naquela época, mesmo sendo ainda muito jovem, aquele momento me chamou a atenção e por essa questão, acredito que naquele instante meu desejo em aprender a tocar trompete tenha sido despertado e hoje percebo que acabei me identificando com aquela situação.

No mesmo período o projeto recebeu doações de instrumentos e como já havia demonstrado meu interesse pelo trompete e era um aluno participativo, a coordenação e os professores resolveram repassar o instrumento para mim. Ali iniciou minha trajetória com esse instrumento que perdura até os dias de hoje atuando como professor e performer.

O foco dessa pesquisa será os caminhos percorridos por trompetistas com formações musicais distintas, buscando compreendê-las e identificá-las a partir da perspectiva da sociologia da educação musical, que para Kraemer "examina as condições sociais e os efeitos da música, assim como relações sociais, que estejam relacionadas com a música." (KRAEMER, 2000, p.57). Com isso, pretendo desvelar em meu trabalho as possíveis trajetórias formativas de trompetistas que atuam no cenário musical de Porto Alegre, considerando que "atuar no cenário musical" será buscar trompetistas colaboradores que atuem dando aulas, tocando em orquestras, grupos de câmara, bandas, eventos e/ou fazendo shows.

Apesar de o trompete ser um instrumento contemplado em alguns cursos de graduação e pós-graduação no Brasil, de maneira geral os trompetistas iniciam seus estudos em bandas escolares, igrejas, projetos sociais e conservatórios e com essa formação seguem atuando como profissionais, tornando-se professores, performers ${ }^{5}$, compositores, maestros e produtores. Como tenho observado em minha trajetória, por já estarem

${ }^{5}$ Segundo o Dicionário Infopédia da Língua Portuguesa performer é um termo utilizado para quem executa e interpreta algo. Nesse caso, utilizo esta palavra em relação aos músicos/trompetistas que atuam interpretando e executando peças musicais em seus mais diversos contextos possíveis. Extraído do site: https://www.infopedia.pt/dicionarios/lingua-portuguesa no dia 08/03/2020.

SOARES, Isac Costa. Especificidades e trajetórias formativas - uma revisão de literatura. Revista da FUNDARTE. Montenegro, p.110-123, ano 20, no 40, janeiro/março de 2020.

Disponível em: http://.seer.fundarte.rs.gov.br/index.php/RevistadaFundarte/index> 31 de março de 2020. 


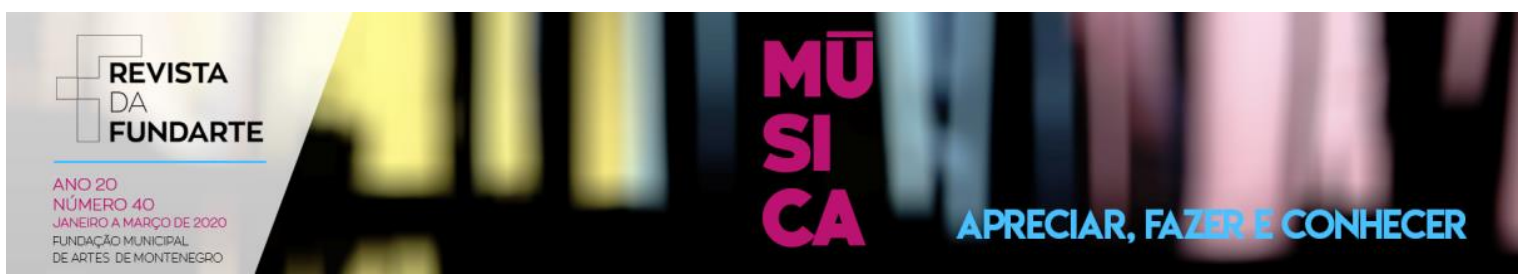

inseridos como profissionais, acabam seguindo na carreira sem buscar uma formação acadêmica.

Por isso, ao longo dos anos venho me interessando em compreender esses percursos formativos. Vários questionamentos surgem ao pensar sobre esse tema, tais como, por que essas pessoas escolheram o trompete? Como iniciaram no instrumento? $\mathrm{O}$ que as motivou a continuar seguindo em suas carreiras como músicos? Como eles vêem suas formações? Que tipos de formações tiveram? Onde atuam com o trompete, são professores, performers, compositores, produtores? $\mathrm{O}$ que esperam de suas carreiras no futuro? Todas essas perguntas me levaram a essa pesquisa na tentativa de compreensão dessas trajetórias.

A partir disso, iniciei uma busca por trabalhos que se assemelhassem a minha proposta de pesquisa. Sendo assim, pesquisei em revistas e sites específicos da área, tais como, ABEM (Associação Brasileira de Educação Musical) e Anppom (Associação Nacional de Pesquisa e Pós Graduação em Música). Além de sites de busca, tais como, google acadêmico, repositório digital da UFRGS conhecido como Lume, entre outros.

Dessa forma, procurei pesquisas que tratassem de trajetórias formativas de trompetistas e através dessa busca inicial, encontrei alguns trabalhos que se assemelham com minha proposta, porém, não encontrei pesquisas que tratassem sobre trajetória, formação ou atuação de trompetistas porto alegrenses. Com isso, irei apresentá-los e explicitá-los nesse artigo de revisão.

\section{Inspiração para o trabalho}

Posso dizer que minha inspiração para este trabalho, veio através de uma leitura inicial da tese de Alexandre Vieira (2017) intitulada TRAJETÓRIAS FORMATIVAS PROFISSIONAIS EM MÚSICA: um estudo com estudantes do Curso Técnico em Instrumento Musical do Instituto Federal de Educação, Ciência e Tecnologia do Ceará - Campus Fortaleza. Nesse trabalho, onde o autor buscou compreender as trajetórias formativas de oito estudantes do curso, utilizando uma

SOARES, Isac Costa. Especificidades e trajetórias formativas - uma revisão de literatura. Revista da FUNDARTE. Montenegro, p.110-123, ano 20, no 40, janeiro/março de 2020.

Disponível em: http://.seer.fundarte.rs.gov.br/index.php/RevistadaFundarte/index> 31 de março de 2020. 


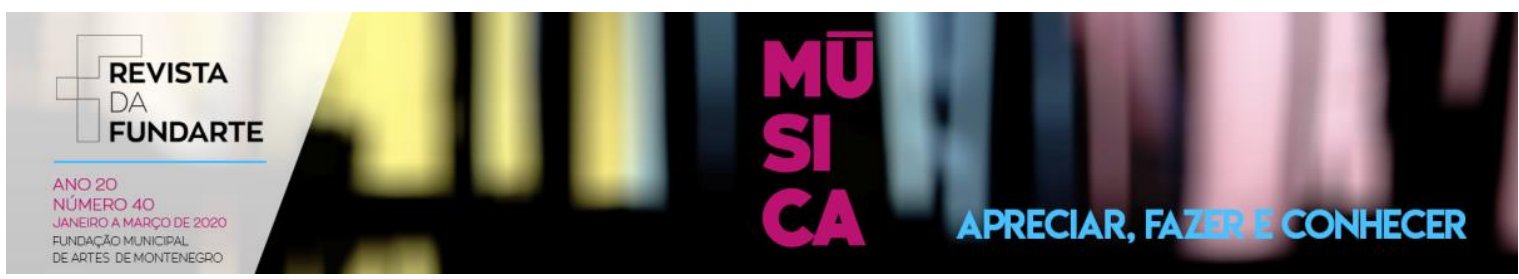

abordagem qualitativa e como metodologia, o estudo de caso, ele discorre sobre o percurso formativo desses alunos, mostrando seus sonhos, objetivos e percalços encontrados no decorrer de suas trajetórias. Essa busca acontece através da própria visão que o autor tem sobre o ser e tornar-se músico/artista, pois, para Vieira (2017)

O artista, como qualquer outra categoria social, se constitui e se alimenta através das referências e conhecimentos que constrói na família, escola, religião e demais grupos e indivíduos com os quais interage ao longo de sua trajetória. Igualmente, instituições específicas de ensino artístico são espaços socialmente reconhecidos, nos quais as técnicas, habilidades, conhecimentos, sensibilidades e significados artísticos são ensinados de maneira sistemática (VIEIRA, 2017, P.30).

A partir dessa perspectiva, o autor traz entrevistas feitas utilizando um roteiro de questões com entrevistas semiestruturadas, a qual ele denominou como "mapa de entrevistas" criando assim, segundo Vieira (2017),

um esquema constituído por pontos possíveis a serem abordados com os estudantes, do que uma sequência linear, que colocasse em risco o que cada um teria de melhor para dividir comigo, sobretudo em relação às suas trajetórias. Iria sim tratá-las como pontos de referência, os quais poderiam ser acessados conforme o fluir das narrativas dos estudantes e pelos direcionamentos provocados por minhas intervenções nas suas falas (VIEIRA, 2017, p. 122).

Em todas as entrevistas aparecem questões pertinentes às perspectivas do tema proposto. Sendo assim, os colaboradores falam sobre o início de suas trajetórias com a música, que caminhos conduziram eles ao curso, o que lá buscavam e, por fim, o que levaram dessa experiência formativa. Mostrando uma visão sensível na busca de compreender essas trajetórias, Vieira (2017) acredita que:

é necessário entender as possibilidades de atuação dos jovens a partir de tamanha inconstância, ou seja, compreender qual o seu campo de ação, seu potencial de intervenção, enquanto atores ativos de suas próprias histórias de vida, perante um futuro que se apresenta cada vez mais embaçado .(VIEIRA, 2017, p. 60).

SOARES, Isac Costa. Especificidades e trajetórias formativas - uma revisão de literatura. Revista da FUNDARTE. Montenegro, p.110-123, ano 20, no 40, janeiro/março de 2020.

Disponível em: http://.seer.fundarte.rs.gov.br/index.php/RevistadaFundarte/index> 31 de março de 2020. 


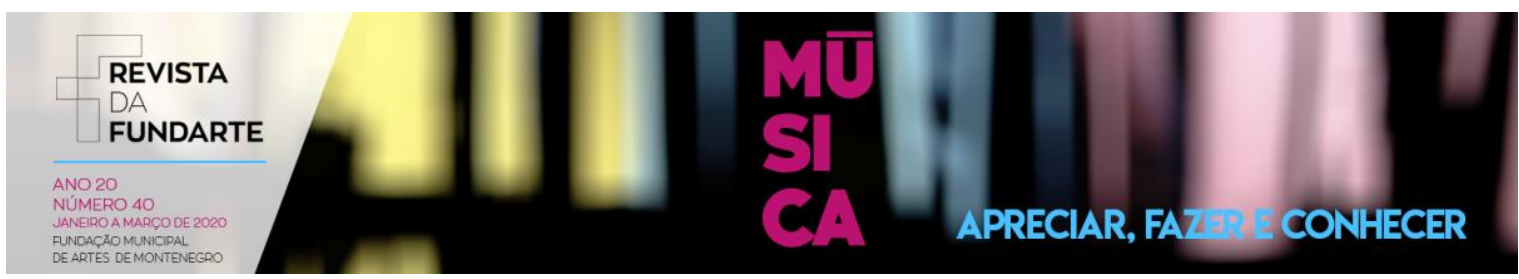

Com esse olhar e, buscando compreender esses trajetos formativos, a tese de Vieira, possibilitou em minha revisão de literatura inicial um melhor entendimento sobre a importância da compreensão dos diversos tipos de formações possíveis em música. Por isso, buscarei trazer essa mesma visão na busca pela compreensão das trajetórias formativas dos trompetistas que colaborarão para minha pesquisa.

\section{Especificidades e trajetórias}

A partir de conversas com minha orientadora, começamos a traçar um delineamento estratégico na divisão do trabalho. Nossa busca foi encontrar uma forma de olhar que propicie na pesquisa uma visão aprofundada em relação as trajetórias dos trompetistas, mostrando suas especificidades nas relações de ensino/aprendizagem, pois, para Souza(2008), "a aprendizagem não se dá num vácuo, mas num contexto complexo. Ela é constituída de experiências que nós realizamos no mundo" (SOUZA, 2008, p. 7), Pensando dessa forma, dividimos o roteiro de questões em três eixos, sendo eles, início da trajetória, período de formação e carreira. Fazendo essa delimitação o projeto começa a se configurar com o objetivo de mostrar de forma mais abrangente os diversos percursos possíveis na carreira dos colaboradores.

Para entender melhor sobre essa delimitação um trabalho que me ajudou a compreender essa questão foi a dissertação e o artigo de Maria Farias (2017), onde a autora discorre sobre o percurso de formação, atuação e identidade profissional de três tecladistas de instrumentos eletrônicos. Amparada pela sociologia da educação musical, da qual, preocupasse com os processos e relações de ensino e aprendizagem de música, ela busca compreendê-los considerando as especificidades do instrumento e os contextos onde estes músicos se formam e atuam. Além disso, nota-se sua preocupação com as questões do uso do teclado eletrônico, suas tecnologias e como elas são exploradas na performance, sala de aula e ensino em geral.

SOARES, Isac Costa. Especificidades e trajetórias formativas - uma revisão de literatura. Revista da FUNDARTE. Montenegro, p.110-123, ano 20, no 40, janeiro/março de 2020.

Disponível em: http://.seer.fundarte.rs.gov.br/index.php/RevistadaFundarte/index> 31 de março de 2020. 


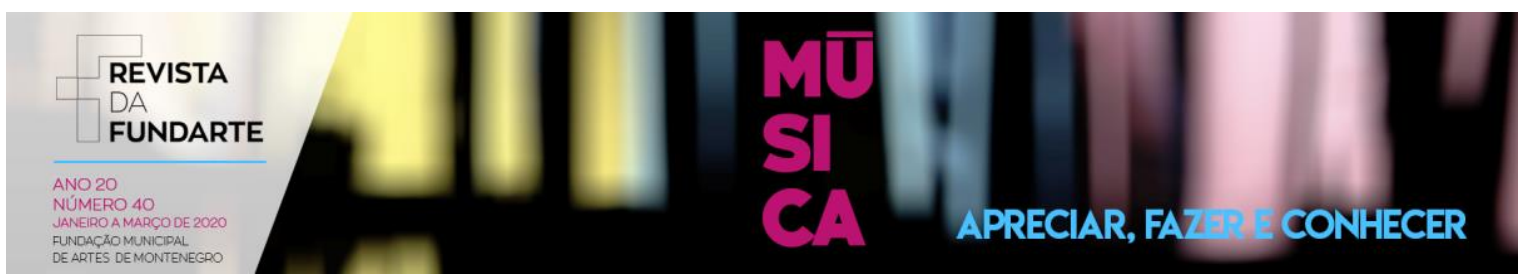

Dividindo o trabalho em três eixos onde ela mostra a formação, atuação e as identidades dos tecladistas, é possível notar como cada colaborador traz em seus relatos significados próprios sobre a profissão. Para FARIAS (2017) "os tecladistas consideram o teclado eletrônico um instrumento versátil - e sua atuação também revelou ser." Além disso, ela também traz especificidades sobre suas atuações que segundo Farias (2017)

A relação que cada tecladista guarda com a tecnologia revela conflitos e contradições que podem ser entendidos como característicos de um músico que atua no encontro de tradições distintas e que propõem paradigmas, até certo ponto, conflitante (FARIAS, 2017, p. 83).

Desta forma, é possível perceber certas particularidades em relação ao ser tecladista.

Tendo como base essas leituras e minha própria experiência empírica no campo, tenho como hipótese que tais trompetistas colaboradores possam ter iniciado seus estudos musicais no seio familiar, bandas escolares, igrejas ou projetos sociais. Esses lugares que citei, são possíveis ambientes onde pode haver a iniciação musical do trompetista. Ainda na dissertação de FARIAS (2007) é possível constatar o processo de aprendizagem musical na infância quando ela relata sobre dois dos seus colaboradores que "tanto Thiago quanto Vini tiveram sua iniciação musical em instrumentos eletrônicos, tendo o teclado como um de seus brinquedos na infância." FARIAS (2017, p. 192). A partir disso, a autora reforça que "a relação com o teclado se desenvolveu e evoluiu à medida que eles próprios se desenvolveram". FARIAS (2017, p. 192). Por isso, trarei em minha pesquisa, além de questões de carreiras, as de formação inicial, pois, como coloquei aqui os trompetistas trazem em si suas especificidades e peculiaridades em relação a iniciação, formação e carreira musical.

Outro trabalho que trago é a dissertação de Gustavo Rauber (2017), em cuja pesquisa ele trata de compreender os percursos formativos de quatro multiinstrumentistas, que para ele "compreende-se como músico multi-instrumentista quem toca vários instrumentos musicais, simultaneamente ou não" RAUBER (2007, SUAKtS, Isac Losta. Especiticidades e trajetorias tormativas - uma revisao de IIteratura. Kevista da FUNDARTE. Montenegro, p.110-123, ano 20, № 40, janeiro/março de 2020.

Disponível em: http://.seer.fundarte.rs.gov.br/index.php/RevistadaFundarte/index> 31 de março de 2020. 


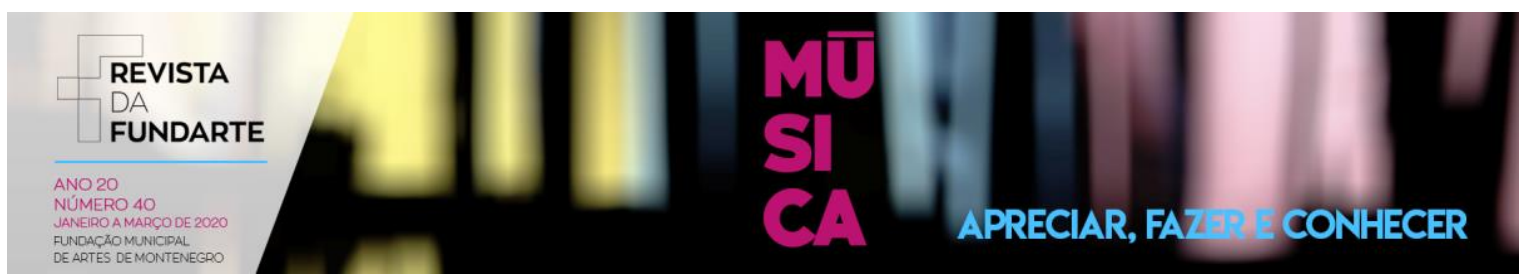

p.7). Assim sendo, com o titulo Percursos de aprendizagem de músicos multiinstrumentistas: Uma abordagem a partir a história oral, o autor traz relatos orais de quatro músicos multi-instrumentistas que na época da pesquisa 2017 residiam no estado do Rio Grande do Sul.

Para essa pesquisa, Rauber (2017) dividiu em dois eixos, sendo eles, formação e atuação. Nesse caso, ele também traz especificidades sobre as formas de ensino/aprendizagem dos músicos multi-instrumentistas. Há relatos que demonstram as particularidades de ser multi-instrumentistas, onde Rauber (2017) aponta, pegando como referência, a fala de um dos colaboradores e a forma como ele pensa sobre tocar mais de um instrumento.

Entre as implicações de tocar mais instrumentos, Cezar considera que o aprendizado de cada um tem "gavetas" que "além de ter a dificuldade de manter os instrumentos a técnica dos instrumentos, tem que manter os repertórios" (RAUBER, 2017, p. 79).

Além disso, há questões especificas de suas atuações, conforme aponta Rauber (2017) em relação a versatilidade que o músico multi-instrumentista acaba desenvolvendo. Para Rauber (2017)

\begin{abstract}
Após a fase de experimentação, na qual o músico exerce os primeiros contatos com novos instrumentos, estes são incorporados pelos músicos às suas rotinas de atuação quando ocorre o reconhecimento das vantagens e benefícios que a prática deste novo instrumento acarretará. Esse processo caracteriza a profissionalização do músico multi-instrumentista que ao buscar melhorar seu desempenho e compreensão sobre o novo instrumento tem a pretensão de autolegitimar essa prática e aperfeiçoar seu rendimento nos diferentes projetos de trabalho entendidos como espaços de socialização e ambientes de profissionalização (RAUBER, 2017, p. 191).
\end{abstract}

Percebe-se que esta questão da especificidade em suas formações e atuações nos trabalhos de Rauber (2017) e Farias (2017), demonstra uma riqueza ao analisar mais profundamente seus trabalhos. Essa preocupação sobre campos de atuação e formação é tratada também no trabalho de Douglas Weiss com Ana Louro (2011) em seu artigo "A formação e atuação de professores de acordeom, na interface de culturas populares e acadêmicas." Nesse trabalho, eles trazem um SOARES, Isac Costa. Especificidades e trajetórias formativas - uma revisão de literatura. Revista da FUNDARTE. Montenegro, p.110-123, ano 20, № 40, janeiro/março de 2020.

Disponível em: http://.seer.fundarte.rs.gov.br/index.php/RevistadaFundarte/index> 31 de março de 2020. 


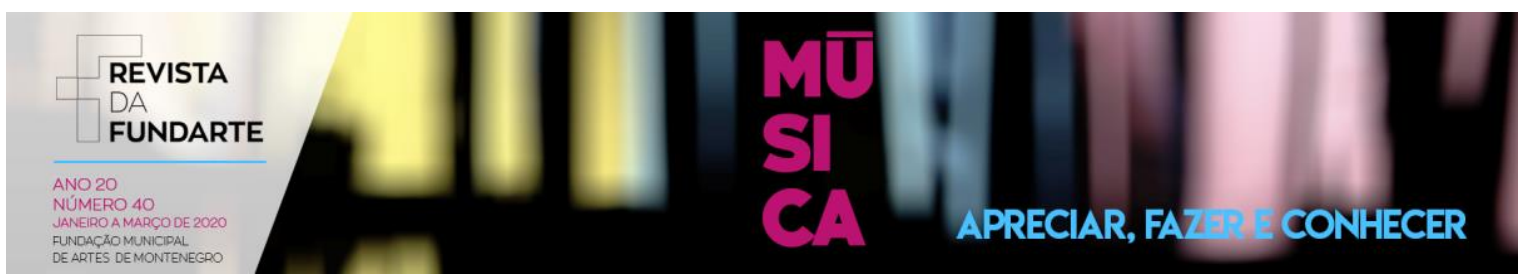

recorte de um projeto de pesquisa focado nas narrativas, colhidas através de uma metodologia de história oral, sobre a formação e atuação de professores de acordeom do sul do Brasil. Através da análise das falas dos professores, eles buscam compreender os aspectos que constituem sua cultura profissional, destacando suas relações com culturas populares e academias. Para Weiss e Louro, "nas trajetórias formativas, os ambientes socioculturais e os dilemas enfrentados são variados, e influenciam na formação da identidade profissional de um indivíduo" (2011, p. 133). Esses dilemas e percalços encontrados nas trajetórias fazem parte de suas formações para além da música, mas de indivíduos que interagem com seu meio social específico, no qual, muitas vezes fazem parte somente daquele ambiente.

\section{Trabalhos específicos sobre trompete}

Os trabalhos que encontrei especificamente sobre trompete estão relacionados ao ensino, história, metodologia e práticas interpretativas. Para essa busca inicial utilizei a página da ABT (Associação Brasileira de Trompetesitas) ${ }^{6}$. A Associação Brasileira de Trompetistas tem contribuído para o compartilhamento de artigos, TCCs, dissertações e teses, pois, dentro do site foi criada uma biblioteca ${ }^{7}$ onde estão sendo compilados os trabalhos já existentes e os mais recentes com temas relacionados à área de práticas relacionadas ao trompete.

Um dos trabalhos mais recentes e que se aproxima de minha ideia inicial é a tese de Flavio da Silva (2019) intitulada "A Construção de um Solista: Um estudo multicasos com trompetistas solistas internacionais. Neste trabalho o autor investiga os processos de formação de um solista internacional de trompete, mediante a

${ }^{6}$ A Associação Brasileira de Trompetistas (ABT) é uma associação jovem que tem como objetivo "promover a integração dos trompetistas brasileiros através do incentivo à performance, pedagogia e produção de literatura ligada ao trompete, mantendo como princípio o respeito à diversidade e à pluralidade de ideias e estilos". Informações retiradas do site: https://abt.art.br/ no dia 08/03/2020.

${ }^{7}$ Segundo o site da Associação Brasileira de Trompetistas (ABT) A Biblioteca Digital da ABT é a oportunidade de, em um só lugar, acessarmos os textos acadêmicos, livros, gravações e partituras, relacionadas ao trompete. Informações retiradas do site: https://abt.art.br/biblioteca no dia 08/03/2020.

SOARES, Isac Costa. Especificidades e trajetórias formativas - uma revisão de literatura. Revista da FUNDARTE. Montenegro, p.110-123, ano 20, № 40, janeiro/março de 2020.

Disponível em: http://.seer.fundarte.rs.gov.br/index.php/RevistadaFundarte/index> 31 de março de 2020. 


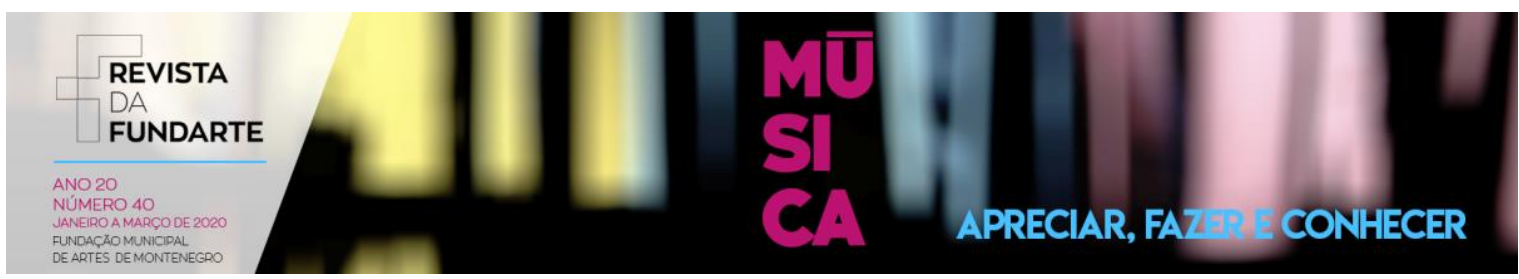

análise da trajetória de vida de nove trompetistas com reconhecida carreira internacional, utilizando como parâmetros de análise os estágios de desenvolvimento propostos pela ciência da expertise. Essa pesquisa se assemelha com minha proposta, pois busca compreender como tais solistas se desenvolveram ao longo de seu percurso e para isso, é feita uma análise em relação a biografia de cada um dos trompetistas escolhidos. Dessa forma, o autor traz singularidades em relação a formação de cada solista ao mesmo tempo em que traça um paralelo entre tais formações.

Sobre o ensino de trompete foram encontrados três trabalhos. São eles: Desenvolvimento da percepção auditiva na aprendizagem do trompete: avaliação de estudos coletivos adotados pelo projeto GURI; dissertação de Jorge Scheffer (2012), Iniciação ao trompete, trompa, trombone, bombardino e tuba: processos de ensino e aprendizagem do método Da Capo; dissertação de Fabrício Vecchia 2008 e Modelos pedagógicos no ensino de instrumentos musicais em modalidade a distância: Projetando o ensino de instrumentos de sopro; dissertação de Leandro Serafim (2014). Além desses, encontrei uma dissertação sobre metodologia intitulada Metodologia De Estudo Para Trompete de Paulo Batista (2010), dois sobre a história do trompete, um chamado Um Repertório Real e Imperial Para os Clarins: Resgate para a História do Trompete no Brasil de Ulises Rolfini (2009), e outro A História do Trompete de Fabio Simão (2007). Por último, encontrei cinco trabalhos relacionados à performance, o que também revela uma preocupação e interesse maior dos trompetistas relacionadas as práticas interpretativas. Me reterei aqui a falar sobre os trabalhos de práticas interpretativas, por não estarem dentro do meu interesse como área de concentração da educação musical.

Todas essas leituras estão contribuindo para o desenvolvimento do meu projeto de pesquisa, e mesmo tendo alguns trabalhos que não se assemelham com o meu, estes servem também para entender o que os trompetistas pesquisadores estão pensando e pesquisando no Brasil.

\section{CONCLUSÃO}

SOARES, Isac Costa. Especificidades e trajetórias formativas - uma revisão de literatura. Revista da FUNDARTE. Montenegro, p.110-123, ano 20, no 40, janeiro/março de 2020.

Disponível em: http://.seer.fundarte.rs.gov.br/index.php/RevistadaFundarte/index> 31 de março de 2020. 


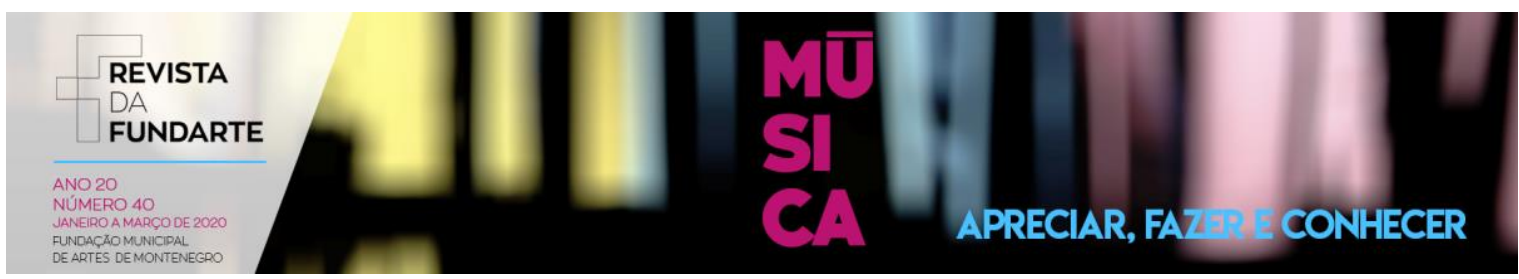

Os trabalhos que encontrei se assemelham, pois, procuram compreender percursos formativos e de atuação de instrumentista, professores e estudantes de música. Nesse caso, notei que há diferentes especificidades nesses campos empíricos que os trabalhos apresentam. Sendo assim, estou organizando meu projeto a partir dessas leituras.

$\mathrm{Na}$ tese de Viera (2017), pude compreender com mais profundidade essa ideia de compreensão de trajetórias, para que assim, através do trabalho de Farias, (2017) eu pudesse organizar de forma mais sistemática os eixos do meu trabalho. Além disso, lendo o trabalho de Rauber (2017), pude observar essas especificidades de atuação e formação trazida nos diálogos dos multi-instrumentistas, colaboradores da pesquisa, e no trabalho de Weiss e Louro trouxe a compreensão dos aspectos que constituem os acordeonistas como professores, mostrando que a formação muitas vezes acontece antes do ingresso na universidade.

Os trabalhos específicos sobre trompete me ajudaram a compreender o que vem sendo produzido e pesquisado sobre o instrumento e, acredito que alguns deles possam ser utilizados como referência em minha pesquisa.

Apesar destes trabalhos não falarem especificamente sobre trajetória formativa de trompetistas, tiveram o papel de trazer a luz da reflexão ao pesquisador que estou me tornando, após minha entrada no mestrado em educação musical na UFRGS (Universidade Federal do Rio Grande do Sul), pois assim pude aprender e compreender como as pesquisas foram feitas. Isso tem me ajudado a refletir e organizar estratégias para o meu próprio trabalho. Além disso, acredito ter sido de suma importância essa revisão inicial, para saber que existem trabalhos que tratam de tais assuntos. Para Alvez (1992)

\footnotetext{
Essa análise ajuda o pesquisador a definir melhor seu objeto de estudo e a selecionar teorias, procedimentos e instrumentos ou, ao contrário, a evitálos, quando estes tenham se mostrados pouco eficientes na busca do conhecimento pretendido. Além disso, a familiarização com a literatura já produzida evita o dissabor de descobrir mais tarde (às vezes, tarde demais) que a roda já tinha sido inventada (ALVEZ, 1992, p. 54).
}

SOARES, Isac Costa. Especificidades e trajetórias formativas - uma revisão de literatura. Revista da FUNDARTE. Montenegro, p.110-123, ano 20, no 40, janeiro/março de 2020.

Disponível em: http://.seer.fundarte.rs.gov.br/index.php/RevistadaFundarte/index> 31 de março de 2020. 


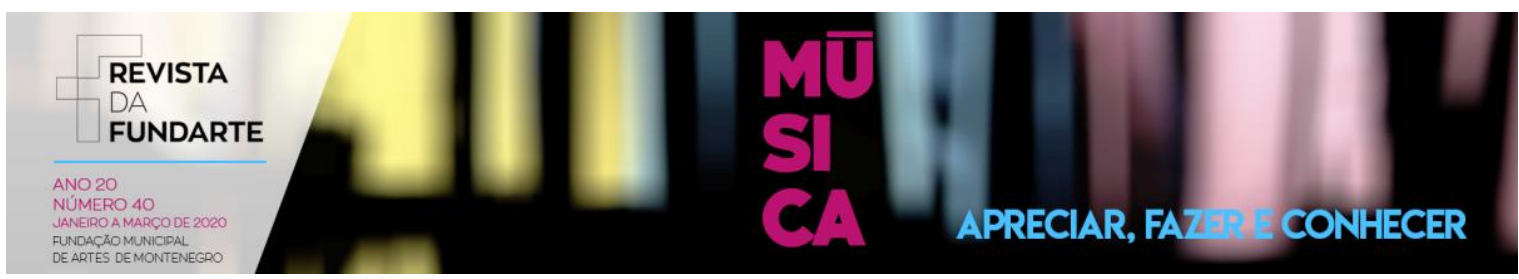

Com isso, acredito que essa revisão tenha cumprido com sua proposta e objetivo inicial, explicitando trabalhos já existentes e os relacionando com meu projeto de pesquisa.

\section{Referencias:}

ALVEZ, Alda Judith. A "Revisão da Bibliografia" em teses e dissertações: meus tipos inesquecíveis. Cadernos de pesquisa, São Paulo, n. 81, p. 53-60, mai. 1992. Disponível em: http://publicacoes.fcc.org.br/ojs/index.php/cp/article/view/990/999 Acesso: 24/06/2019

CASTRO, Claudio de Moura. REVISTA VEJA, No 41 - ano 37. - Ed. Abril. 13 de outubro de 2004.

COTANDA, Fernando C; SILVA M. K; ALMEIDA M. L; ALVEZ, C. F. Ciências humanas - Pesquisa e Método [Organizado por] Céli Regina Jardim Pinto e Cesar Barcellos Guazzelli - Porto Alegre: Editora da UFRGS, 2008.

FARIAS, Maria Amélia Benincá. Formação, atuação e identidades musicais de tecladistas de instrumentos eletrônicos: Um estudo de caso. 2017, 227f. Dissertação (Mestrado em Música - Educação Musical), Programa de Pós Graduação em Música, Universidade Federal do Rio Grande do Sul, Porto Alegre, 2017.

KRAEMER, Rudolf-Dieter. Dimensões e funções do conhecimento pedagógicomusical. Tradução de Jusamara Souza. Em Pauta. Porto Alegre, v. 11, n. 16/17, p. 50-73, 2000.

RAUBER, Gustavo Luís. Percursos de aprendizagem de músicos multiinstrumentista: Uma abordagem partir da história oral. 2017, 230f. Dissertação (Mestrado em Música - Educação Musical), Programa de Pós Graduação em Música, Universidade Federal do Rio Grande do Sul, Porto Alegre, 2017.

PENNA, Maura. Construindo o primeiro projeto de pesquisa em educação e música. Porto Alegre: Sulina, 2015.

SOUZA, Jusamara Vieira. Aprender e ensinar música no cotidiano / org. por Jusamara Souza. - Porto Alegre: Sulina, 2008. 287.p (Coleção Musicas)

VIEIRA, Alexandre. Trajetórias formativas profissionais em música: um estudo com estudantes do Curso Técnico em Instrumento Musical do Instituto Federal de Educação, Ciência e Tecnologia do Ceará - Campus Fortaleza. Tese (Doutorado em Música) - Programa de Pós-Graduação em Música, Universidade Federal do Rio Grande do Sul, Porto Alegre, 2017. Disponível em: <https://lume.ufrgs.br/bitstream/

SOARES, Isac Costa. Especificidades e trajetórias formativas - uma revisão de literatura. Revista da FUNDARTE. Montenegro, p.110-123, ano 20, no 40, janeiro/março de 2020.

Disponível em: http://.seer.fundarte.rs.gov.br/index.php/RevistadaFundarte/index> 31 de março de 2020. 


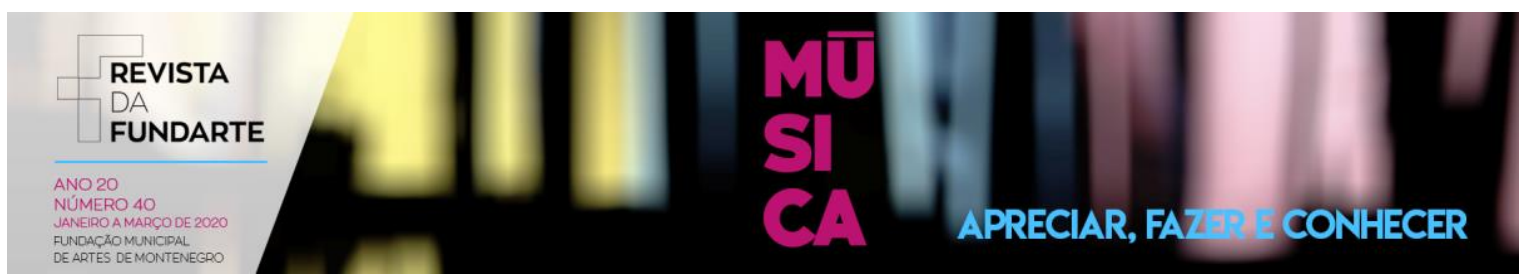

handle/10183/158931/001023060. pdf?sequence=1\&isAllowed=y>. Acesso em: 21 ago. 2018.

WEISS, Douglas Rodrigo Bonfante; LOURO, Ana Lúcia de Marques. A formação e atuação de professores de acordeom na interface de culturas populares e acadêmicas. Revista ABEM, Londrina, v. 19, n. 26, p. 132-144, jul./dez, 2011. Disponível em: <http://www.abemeducacaomusical.com.br/revista_abem/ed26/revis ta26_artigo11.pdf>. Acesso em: 21 ago. 2018.

SOARES, Isac Costa. Especificidades e trajetórias formativas - uma revisão de literatura. Revista da FUNDARTE. Montenegro, p.110-123, ano 20, no 40, janeiro/março de 2020.

Disponível em: http://.seer.fundarte.rs.gov.br/index.php/RevistadaFundarte/index> 31 de março de 2020. 